\title{
Steroid Hormone Runoff from Agricultural Test Plots Applied with Municipal Biosolids
}

\author{
Yun-Ya Yang, ${ }^{\dagger}$ James L. Gray, ${ }^{\ddagger}$ Edward T. Furlong, ${ }^{\ddagger}$ Jessica G. Davis, ${ }^{\dagger}{ }^{\S}$ Rhiannon C. ReVello, ${ }^{\ddagger}$
} and Thomas Borch*, ${ }^{\dagger}, \|$

\footnotetext{
${ }^{\dagger}$ Department of Soil and Crop Sciences, Colorado State University, Fort Collins, Colorado 80523-1170, United States

${ }^{*}$ National Water Quality Laboratory, U.S. Geological Survey, Denver Federal Center, Denver, Colorado 80225-0046, United States

${ }^{\S}$ Institute for Livestock and the Environment, Colorado State University, Fort Collins, Colorado 80523-1170, United States

"Department of Chemistry, Colorado State University, Fort Collins, Colorado 80523-1872, United States
}

\section{Supporting Information}

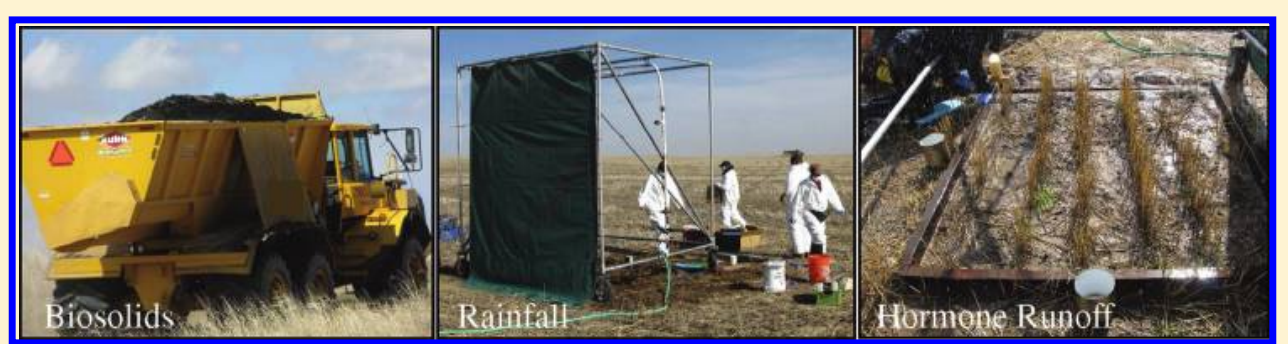

ABSTRACT: The potential presence of steroid hormones in runoff from sites where biosolids have been used as agricultural fertilizers is an environmental concern. A study was conducted to assess the potential for runoff of seventeen different hormones and two sterols, including androgens, estrogens, and progestogens from agricultural test plots. The field containing the test plots had been applied with biosolids for the first time immediately prior to this study. Target compounds were isolated by solid-phase extraction (water samples) and pressurized solvent extraction (solid samples), derivatized, and analyzed by gas chromatographytandem mass spectrometry. Runoff samples collected prior to biosolids application had low concentrations of two hormones (estrone $<0.8$ to $2.23 \mathrm{ng} \mathrm{L}^{-1}$ and androstenedione $<0.8$ to $\left.1.54 \mathrm{ng} \mathrm{L}^{-1}\right)$ and cholesterol $\left(22.5 \pm 3.8 \mu \mathrm{g} \mathrm{L}^{-1}\right)$. In contrast, significantly higher concentrations of multiple estrogens $\left(<0.8\right.$ to $\left.25.0 \mathrm{ng} \mathrm{L}^{-1}\right)$, androgens $\left(<2\right.$ to $\left.216 \mathrm{ng} \mathrm{L}^{-1}\right)$, and progesterone $\left(<8\right.$ to $\left.98.9 \mathrm{ng} \mathrm{L}^{-1}\right)$ were observed in runoff samples taken 1,8 , and 35 days after biosolids application. A significant positive correlation was observed between antecedent rainfall amount and hormone mass loads (runoff). Hormones in runoff were primarily present in the dissolved phase $(<0.7-\mu \mathrm{m}$ GF filter), and, to a lesser extent bound to the suspended-particle phase. Overall, these results indicate that rainfall can mobilize hormones from biosolids-amended agricultural fields, directly to surface waters or redistributed to terrestrial sites away from the point of application via runoff. Although concentrations decrease over time, 35 days is insufficient for complete degradation of hormones in soil at this site.

\section{INTRODUCTION}

The presence of endocrine-disrupting chemicals (EDCs) in the environment, including natural and synthetic hormones, has become a growing concern because low part-per-trillion concentrations of these chemicals have caused adverse impacts on aquatic organisms. ${ }^{1,2}$ Possible sources of hormones to the environment include discharges from wastewater treatment plants (WWTPs), ${ }^{3-5}$ use of reclaimed water for irrigation, ${ }^{6}$ domestic septic systems, ${ }^{7}$ effluents from concentrated animal feeding operations (CAFOs), ${ }^{8-10}$ and runoff from agricultural fields where manure and biosolids (organic-rich solids resulting from treatment of sewage sludge) are applied as fertilizers and soil amendments. ${ }^{11-13}$

Numerous laboratory studies have investigated the persistence and degradation pathways of hormones in manure, ${ }^{14,15}$ WWTP-affected streams and groundwater, ${ }^{16,17}$ and biosolids. ${ }^{18,19}$ However, most studies investigating the behavior of hormones in manure or biosolids-amended soils have been conducted under laboratory rather than field conditions. Jacobsen et al. ${ }^{11}$ investigated the impact of biosolids amendments to soils on testosterone degradation in laboratory microcosms. The observed inhibition of $\left[{ }^{14} \mathrm{C}\right]$-testosterone mineralization in a loam soil heavily amended with biosolids was suggested to result from inhibition of microbial activity or increased sorption. Stumpe and Marschner ${ }^{20}$ conducted laboratory incubation experiments to determine the mineralization potential of $17 \beta$-estradiol $(\beta \mathrm{E} 2)$ and testosterone in soils with long-term biosolids application and wastewater irrigation, and found that for $\beta \mathrm{E} 2$ the mineralization rate $(5-7 \%)$ was

Received: November 1, 2011

Revised: January 24, 2012

Accepted: January 29, 2012

Published: January 30, 2012 
lower and the sorption affinity was higher than for testosterone in all test soils. Long-term application of biosolids had no effect on the 21-day hormone mineralization rates while long-term irrigation with wastewater did, likely due to soluble sorbents (e.g., colloidal and dissolved organic matter) decreasing bioavailability. In another recent study, mineralization of estrogens was not related to changes in sorption parameters, rather it was enhanced by up to $147 \%$ or depressed by up to $50 \%$, depending on site characteristics and the type of organic waste applied (i.e., manure, biosolids, wastewater). ${ }^{21}$ In sum, these studies show that while these hormones can be transformed in agricultural settings, they likely persist long enough to potentially impact the quality of runoff water.

Other studies have indicated that land application of manure can result in hormone leaching and runoff. ${ }^{12,22}$ Agricultural management practices such as tillage and rate of manure application may also affect the eventual exports of steroid hormones in runoff. Compared with raw litter and reduced tillage, no-tillage and pelletized litter treatments yielded much lower exports and concentrations of estrogens, indicating that pelletized litter and no-tillage could be used as best management practices to reduce estrogen exports from agricultural fields. ${ }^{23}$ Testosterone $\left(6-19 \mathrm{ng} \mathrm{L}^{-1}\right)$ and $\beta \mathrm{E} 2$ (19-389 ng $\left.\mathrm{L}^{-1}\right)$ were observed in runoff following poultry litter application depending on tillage conditions, ${ }^{24}$ whereas another study detected $\beta \mathrm{E} 2\left(6-66 \mathrm{ng} \mathrm{L} \mathrm{L}^{-1}\right)$ in groundwater adjacent to fields amended with poultry litter and cattle manure. ${ }^{25}$ Nichols et al. $^{24}$ demonstrated that field-applied poultry litter can contribute $\beta \mathrm{E} 2$ to runoff, and amending poultry litter with alum reduced mean $\beta \mathrm{E} 2$ concentrations. Finlay-Moore et al. ${ }^{25}$ measured the $\beta \mathrm{E} 2\left(20-2530 \mathrm{ng} \mathrm{L}^{-1}\right)$ and testosterone (10$1830 \mathrm{ng} \mathrm{L}^{-1}$ ) in runoff water and soil from poultry (broiler) litter-amended grasslands. In field soil, the highest observed concentration of $\beta \mathrm{E} 2$ and testosterone was 675 and $165 \mathrm{ng}$ $\mathrm{kg}^{-1}$, respectively. In these studies, runoff concentration appeared strongly dependent on the litter application rate and frequency. ${ }^{24,25}$

Mansell et al. ${ }^{10}$ investigated soil and runoff concentrations in simulated rainfall experiments from steer feedlots. Whereas only three of the six hormones they measured were detected in fresh manure, all six were detected in surficial soil after two weeks. This is likely due to conversion of testosterone to androstenedione and $\alpha \mathrm{E} 2$ to $\mathrm{E} 1$ and $\beta \mathrm{E} 2$ as the soil aged. Androstendione and progesterone in aged soils were present at levels much higher than could be accounted for by antecedent levels of testosterone. Other research indicates that both of these compounds can be generated microbially from sterols that are likely to be present in manure as well as in biosolids. ${ }^{26}$

In the United States, it is estimated that the average WWTP produces $240 \mathrm{~kg}$ dry weight of solids per million liters of wastewater treated, resulting in approximately 8 million tons (dry weight basis) of biosolids produced per year, of which about $50 \%$ is land applied. ${ }^{27}$ Surprisingly, little is known about the potential for runoff of hormones after land application of biosolids, although some inferences can be drawn from the existing studies conducted with manure and poultry litters which indicate that hormones can be mobilized from solid material by rainfall. Agricultural operations both through livestock emission and spreading of manure can be an important source of hormones to the environment. ${ }^{28}$ Thus, the main objectives of this study were to evaluate the potential for hormone (compounds listed in Table S1 of the Supporting
Information) runoff from agricultural test plots applied with biosolids and to elucidate the major transport mechanisms.

\section{EXPERIMENTAL SECTION}

Experimental Site and Sample Collection. During April to June 2008, three experimental plots $\left(6 \mathrm{~m}^{2} ; 2 \mathrm{~m}\right.$ wide by $3 \mathrm{~m}$ long) in eastern Colorado (latitude $40^{\circ} 06^{\prime} 08^{\prime \prime} \mathrm{N}$, longitude $104^{\circ} 12^{\prime} 43^{\prime \prime} \mathrm{W}$, Figure S1) were established. The experimental plots are located in a dryland winter wheat field (wheat-fallow rotation) with reduced tillage, typical of the fields receiving biosolids from Colorado. Rainfall simulations replicating a 100year rainfall event (approximately $65 \mathrm{~mm} \mathrm{hr}^{-1}$ ) were performed 5 days before, and 1,8 , and 35 days after routine biosolids application. Biosolids had not been previously applied to this site. The biosolids applied to the test plots were produced through anaerobic digestion and dewatering of concentrated solids from primary and secondary treatment at an urban wastewater treatment plant in Colorado. The actual application rate was about 3.5 dry metric tons of biosolids per hectare. Immediately after application, the biosolids were partially incorporated into the soil with a chisel plow to a depth of about $15 \mathrm{~cm}$. The plots were established parallel to the slope $(\sim 3 \%)$, and the soil at the lowest position (plot 1) had the finest texture and most gentle slope (Table S2, Figure S1). Before each simulated rainfall, soil samples were collected from locations outside the experimental plots in tared cans, at depths of $0-2,2-6$, and $6-10 \mathrm{~cm}$ for soil moisture measurement (Figure S2). Cans were weighed, dried at 105 ${ }^{\circ} \mathrm{C}$ for $24 \mathrm{~h}$, and then weighed again to determine soil moisture. Soil was sampled at 9 randomly selected points in the $0-10 \mathrm{~cm}$ layer. The 9 samples were combined to yield one composite sample for soil properties analysis. The soil type on the experimental site was loamy sand (\% sand/silt/clay: $82 / 12 / 6$ ) to sandy loam (\% sand/silt/clay: $86-88 / 8-9 / 4-5$; Table S2).

Artificial rainfall was applied to each $6-\mathrm{m}^{2}$ plot with a rainfall simulator that used a Teejet $1 / 2 \mathrm{HH}$-SS50WSQ nozzle placed in the center of the simulator. ${ }^{29}$ The nozzles and associated water piping, pressure gauge, and electrical wiring were mounted on an aluminum frame. The simulator was placed approximately $3 \mathrm{~m}$ above the soil surface, and hormone-free well water was used in all experiments $(\mathrm{pH}=6.5-7, \mathrm{EC}=$ $\left.0.04-2 \mathrm{dS} \mathrm{m} \mathrm{m}^{-1}\right)$. Metal borders were installed $(0.2-\mathrm{cm}$ thick and $15.2-\mathrm{cm}$ wide) $7 \mathrm{~cm}$ above ground and $9.25 \mathrm{~cm}$ below ground to isolate surface runoff. A runoff collection gutter was installed at the down-slope edge of each plot to divert runoff to the collection point. Calibration cans were placed at three sides of the plot to collect rainfall in order to determine the uniformity of flow over the plot. Runoff and particulate matter yields from each 6- $\mathrm{m}^{2}$ plot were measured during each experiment. The runoff flow rate was measured as described previously. ${ }^{30}$ Rainfall was applied and periodic samples were collected until ca. steady-state runoff rate was observed (30-60 min per test). Twelve runoff samples were collected in 1-L amber glass bottles from each plot through the course of each simulated rainfall event, and then placed on ice in the dark and transported to the laboratory. The 12 runoff samples collected from each experiment were then composited into 3 samples using a cone splitter, representing the early, middle, or late periods of the rainfall event. A total of 33 composited samples collected from three experimental plots were analyzed. Isotopedilution standards (IDSs) were added to each sample (Tables S3 and S4), and samples were stored at $-60{ }^{\circ} \mathrm{C}$ in high-density polyethylene (HDPE) containers until analysis. The samples 


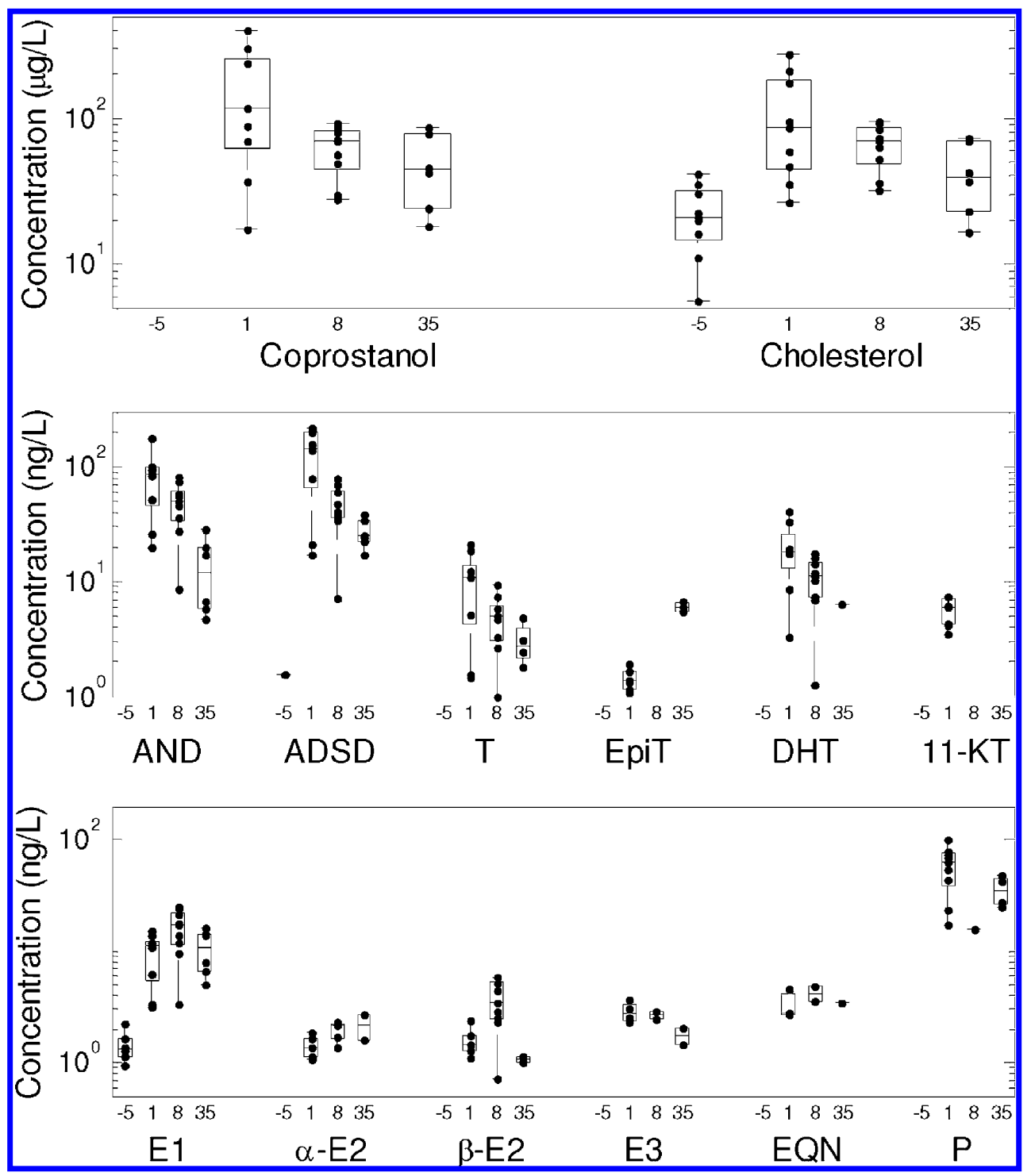

Figure 1. Boxplot showing runoff concentration distribution of detected compounds in a total of nine runoff samples collected from all three plots during simulated rainfall 5 days prior to biosolids application $(-5)$ and 1, 8, and 35 (no measurements were made from plot 3 on day 35 ; six runoff samples were analyzed) days afterward. Boxes indicate 25th and 75th percentile values and whiskers are drawn to the highest and lowest data points that are not outliers (AND: cis-androsterone; ADSD: androstenedione; T: testosterone; EpiT: epitestosterone; DHT: dihydrotestosterone; 11-KT: 11-ketotestosterone; E1: estrone; $\alpha$-E2: $17 \alpha$-estradiol; $\beta$-E2: 17 $\beta$-estradiol; E3: estriol; EQN: equilenin; P: progesterone).

were extracted and analyzed without filtration, so reported concentrations include both dissolved and suspended-particle bound hormones.

To investigate the primary phase responsible for transporting hormones, the percentage of hormones partitioned to the suspended-particle bound phase and in the dissolved phase were determined for a subset of unfiltered runoff samples by filtering the runoff through a $0.7-\mu \mathrm{m}$ (nominal) glass-fiber filter (Whatman GF/F, $142 \mathrm{~mm}$ diameter, Whatman Inc. Piscataway, NJ). Both the filter and the filtrate were retained and analyzed.

A composite biosolids sample was collected from several points within the pile applied to the field at the time of application. This composite sample was subsampled in the laboratory 5 times (denoted biosolids A-E) and analyzed for the same 19 compounds determined in the water analyses. All subsamples were taken from one jar and were intended to provide an estimate of method and sampling variability and precision (Table S5).
Sample Analysis. Seventeen natural and synthetic hormones, comprising nine estrogens, six androgens, and two progestins, and two related sterols were measured in unfiltered (combined dissolved and suspended-particle bound phases) and filtered runoff, filtered suspended particles, and biosolids samples (Table S1). Many of the hormones have previously been detected in biosolids, so biosolids application to agricultural fields represents a viable source to the environment. ${ }^{19,31}$ Although the sterols (cholesterol and coprostanol) are not hormonally active, they are typically present in biosolids at high concentration and are useful for comparative purposes.

Standards and reagents are described in the SI. Prior to use, all glassware was silanized. Hormones were extracted from filtered or unfiltered runoff samples using $\mathrm{C}_{18}$ solid-phase extraction (SPE) disks and isolated using Florisil cartridges; hormones in the suspended-particle bound phase from filters and biosolids samples were extracted using pressurized solvent extraction (PSE), and interferences were removed by isolation 


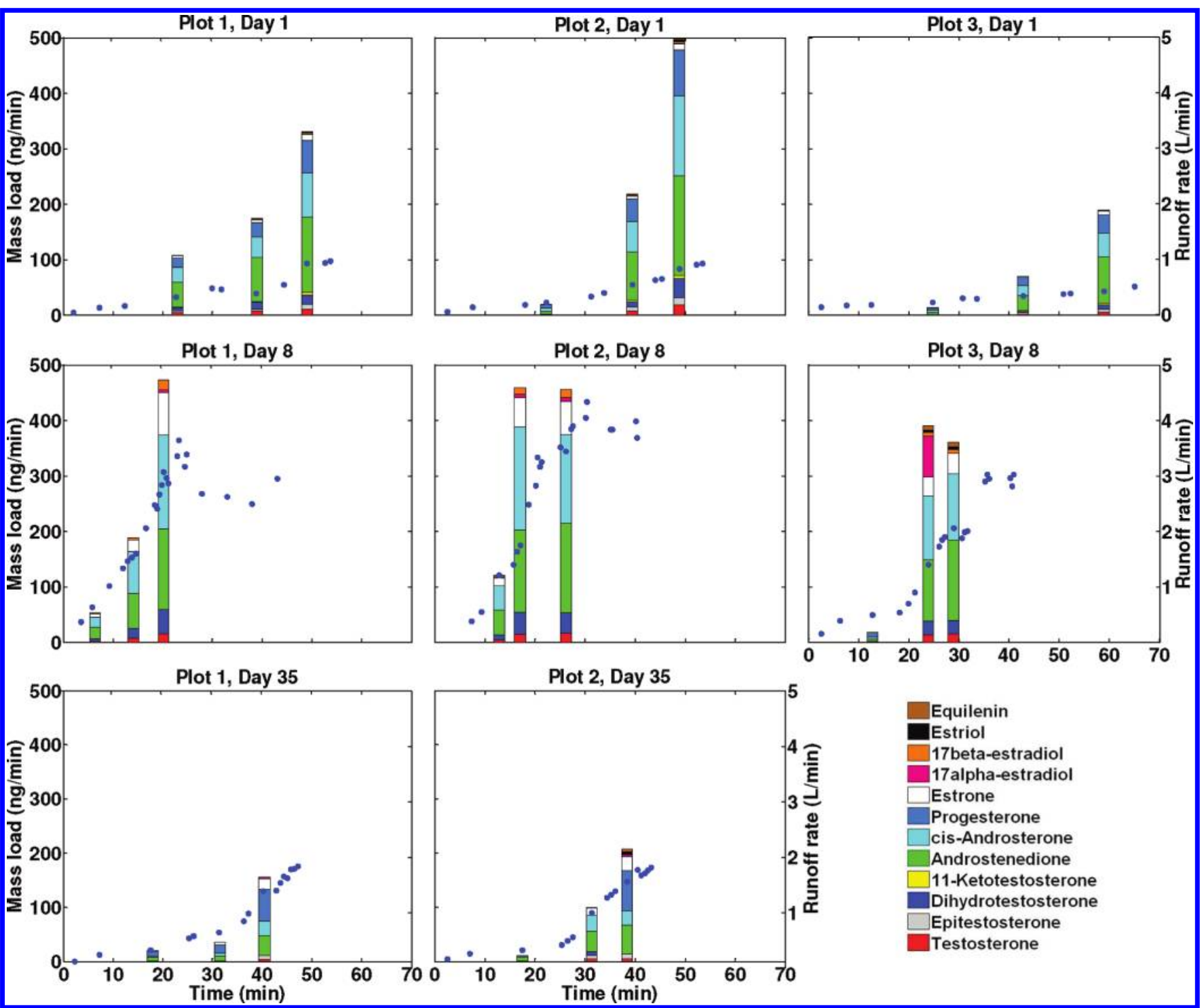

Figure 2. Hormone mass load and runoff rate (blue circles on secondary axis) from all three plots 1 day, 8 days, and 35 days after biosolids application. No measurements were made for plot 3 on day 35 .

on OASIS HLB cartridges and elution across Florisil cartridges. Both SPE and PSE extracts were derivatized with activated $N$ methyl-(N-trimethylsilyl)trifluoroacetamide (MSTFA, SigmaAldrich) and analyzed by gas chromatography-tandem mass spectrometry (GC/MS/MS). More detail on extraction, isolation, and analysis can be found in Foreman et al. ${ }^{32}$ The PSE extraction and sample cleanup was modified after the method of Burkhardt et al.; ${ }^{33}$ the only difference was that Florisil cartridges were eluted with 95\% dichloromethane (DCM)/5\% methanol rather than a DCM/diethethyl ether solvent mixture. The derivatization and instrumental analysis was carried out as in the water method with the exception that $500 \mu \mathrm{L}$ of MSTFA was used (versus $200 \mu \mathrm{L}$ ) to minimize reagent limitations previously observed in the more complex solid extract matrix.

Quality Assurance/Quality Control. Throughout the study, regular verification of method performance was conducted in the form of spike-recovery experiments and analysis of blank samples. At least one spike and one blank was analyzed per set of 10 samples, for a total of 8 of each during the course of the study. For all target compounds, spike recovery averaged $93 \pm 11.6 \%$, ranging from $71 \pm 14.9 \%$ (equilin) to $116 \pm 22.0 \%$ (cholesterol) (Table S3). Seventeen of 19 compounds were never detected in blank samples, two compounds (cholesterol and coprostanol) are commonly observed in method blanks, but neither ever exceeded censoring levels. For every sample, IDS response was evaluated independently to estimate absolute compound recovery, although reported results are recovery corrected by isotope dilution. Recovery of IDS compounds averaged 57.7\%; for individual compounds average recovery during the study ranged from $46 \pm 17.5 \%$ (cholesterol-d7) to $71 \pm 19.1 \%$ (estrone-d4) (Table S4).

Statistical Analysis. Pearson's correlation analysis was performed using SAS PROC CORR (version 9.2) on hormone mass loads and antecedent rainfall amount.

\section{RESULTS AND DISCUSSION}

Steroid Hormone Runoff during a Series of Rainfall Events. Six out of seventeen hormones were detected in the biosolids samples, representing a wide range of concentrations (Table S5). Estrone was found at highest concentration (78 \pm 
$\left.5.8 \mathrm{ng} \mathrm{g}^{-1}\right)$ in biosolids, followed by androstenedione $(22 \pm 5.3$ $\left.\mathrm{ng} \mathrm{g}^{-1}\right)$ and cis-androsterone $\left(18 \pm 1.4 \mathrm{ng} \mathrm{g}^{-1}\right)$. Twelve of the seventeen hormones, coprostanol, and cholesterol were detected in at least one unfiltered runoff sample during the experimental period (Tables S6 and S7). Four synthetic hormones, diethylstilbestrol, norethindrone, ethinyl estradiol, and mestranol, were not detected in any of the samples, nor was equilin, a natural estrogen that is used in hormone replacement therapy (Tables S6 and S7). In the rainfall simulation 5 days prior to biosolids application, only androstenedione (one of nine samples, $1.54 \mathrm{ng} \mathrm{L}^{-1}$ ), estrone (six of nine samples 0.95 to $2.23 \mathrm{ng} \mathrm{L}^{-1}$ ), and cholesterol (nine of nine samples, $22.5 \pm 3.8 \mu \mathrm{g} / \mathrm{L}$ ) were detected in runoff (Table S6).

In contrast, significant concentrations of hormones were observed in runoff samples one day after biosolids application (Figure 1). One day after biosolids application, 14 of 19 compounds were observed in runoff with $82.5 \%$ detection frequency among detected compounds. The average concentrations of coprostanol and cholesterol in runoff were 153 and $112 \mu \mathrm{g} \mathrm{L}^{-1}$, respectively. The hormones that were detected were present at parts-per-trillion concentrations $\left(\mathrm{ng} \mathrm{L}^{-1}\right)$. Runoff samples collected one day after biosolids application contained significantly $(p<0.05)$ higher concentrations of estrogens, as well as androgens and progesterone based on Pearson's correlation analysis (Figures S3-S5). Overall, estrogen (E1, $\alpha \mathrm{E} 2, \beta \mathrm{E} 2$, and estriol (E3)), androgen (testosterone, epitestosterone, 11-ketotestosterone, cis-androsterone, and androstenedione), and progestogen (progesterone) concentrations one day after biosolids application ranged from $<0.8$ to $15 \mathrm{ng} \mathrm{L}^{-1},<2$ to $220 \mathrm{ng} \mathrm{L}{ }^{-1}$, and 17 to $98.9 \mathrm{ng} \mathrm{L}^{-1}$, respectively (Table S6).

Concentrations $\left(\mathrm{ng} \mathrm{L}^{-1}\right)$ for each rainfall event are shown averaged across plots for different time points (Figure 1), and generally decreased or remained constant for most compounds from day 1 to day 35. Increased runoff rate as soil became saturated meant that hormone load $\left(\mathrm{ng} \mathrm{min}^{-1}\right)$ increased substantially over the course of each rainfall simulation (Figure 2 ). The mass load was calculated as follows: Mass load (ng $\left.\min ^{-1}\right)=$ Runoff rate $\left(\mathrm{L} \mathrm{min}{ }^{-1}\right) \times$ Runoff concentration (ng $\left.\mathrm{L}^{-1}\right)$.

Furthermore, for compounds that were not detected in $100 \%$ of samples, the nondetections were clustered during the early periods of runoff sampling. At 8 and 35 days after biosolids application (Table S6 and Figure S3-S5), similar patterns of generally lower concentrations and lower frequency of detection $(42.1 \%$ detections on day $8,58.3 \%$ on day 35 ) were observed.

The runoff patterns observed for each of the hormones during the experimental period are likely associated with differences in partitioning behavior, (bio)transformation, and (de)conjugation of the individual compounds. Mean concentrations of hormones detected in biosolids samples ranked in the following order: E1 > androstenedione > cis-androsterone > progesterone. This order suggests that both the initial hormone concentration in biosolids and physicochemical properties affect the observed runoff concentrations. Some observed hormones may be generated microbially from sterols or through interconversion of hormones, as other studies have observed increases of androstenedione and progesterone in manure ${ }^{34}$ and manure-impacted soils ${ }^{10}$ as they aged. However, the concentrations of androgens in runoff had decreased by day 8 and day 35, which is consistent with previous reports and suggests that biodegradation or mass loss via leaching may also be an important factor affecting runoff concentrations. ${ }^{11,35}$

Observed runoff concentrations could also be affected by differential rates of in situ degradation for the hormones after biosolids application to the soil. Previous batch, column, and field studies have also shown that the sorption affinity of testosterone is lower, while the dissipation/transformation rate and potential for migration is higher than for $\beta \mathrm{E} 2 .^{20,25,35}$

These results demonstrate that runoff from biosolidsamended agricultural soils can transport hormones laterally off-field, and suggest that such runoff could be an important source of hormones to receiving waters, especially in areas where application of biosolids is common, and where a substantial portion of surface water flow is derived from such runoff. $^{2}$ Further, runoff from these experiments had hormone concentrations that exceed biological effects thresholds ${ }^{1}$ (Figure 1), suggesting potential for effects on aquatic organisms exposed to such runoff. However, the rainfall rate used in the experiments corresponds to a 100-year rain event for eastern Colorado, so these results likely represent an upper bound on hormone runoff at this site.

Among the hormones, androstenedione was found in the highest concentration in runoff on day 1 , followed by cisandrosterone and progesterone. Temporal trends in hormone load were similar among the three plots (Figure 2). However, the runoff concentrations of hormones observed at day 1 after biosolids application followed the order androstenedione $>$ cisandrosterone $>$ progesterone $\gg \mathrm{E} 1$. The fact that testosterone, epitestosterone, 11-ketotestosterone, $\alpha \mathrm{E} 2$, and $\beta \mathrm{E} 2$ were observed in runoff samples but not in biosolids is likely due to less sensitivity of solid versus liquid analytical methods, although microbial production of these hormones as the soil aged is possible.

One day after biosolids application, the concentration of androstenedione was between 1 and 2 orders of magnitude higher than $\mathrm{E} 1$ or $\beta \mathrm{E} 2$ (Figure 1 and Table S6). In general, the highest concentrations of androgens in runoff occurred on the first day after biosolids application. For example, in plot 1, the runoff concentrations of testosterone, dihydrotestosterone, androstenedione, and cis-androsterone decreased by $50-75 \%$ from day 1 to day 8 , and decreased again by more than $44 \%$ from day 8 to day 35 (Figure S3). Similar trends were observed for runoff concentrations of coprostanol and cholesterol. In plot 1 on day 1 , the highest concentration of coprostanol and cholesterol were 400 and $280 \mu \mathrm{g} \mathrm{L}^{-1}$, respectively (Table S6). Conversely, in plot 1 , the runoff concentrations of $\mathrm{E} 1$ and $\beta \mathrm{E} 2$ increased by more than $42 \%$ from day 1 to day 8 , but decreased by more than $40 \%$ from day 8 to day 35 (Figure S3).

In contrast to the androgens, total estrogen (i.e., E1, $\alpha \mathrm{E} 2$, and $\beta \mathrm{E} 2)$ runoff concentrations did not markedly decrease in the month following biosolids application. Previous studies have suggested that the most predominant factors contributing to the fate and transport of $\beta \mathrm{E} 2$ and testosterone in the field were soil-water status (i.e., soil moisture percentage), organic matter content, and colloid-facilitated transport. ${ }^{20}$ The higher runoff rate observed during the second simulated rainfall event (day 8) after biosolids application is likely due to the high antecedent moisture content of the soil (Figure S2) and intervening natural rain $(25.4 \mathrm{~mm}$ rain between days 1 and 8 ). The total estrogen concentration in runoff at day 35 still exceeds biological effects thresholds. ${ }^{1}$ The concentrations of E1 were found to be consistently greater than $\alpha \mathrm{E} 2$ and $\beta \mathrm{E} 2$ for all simulated rainfall events. 
Finally, the runoff concentrations of progesterone were reduced at least $87 \%$ at day 8 , and then increased to a level similar to day 1 on day 35 (Figure S3, Tables S6 and S7). The trends observed in plots 2 and 3 are provided in SI Figures S4 and S5. The concentration of progesterone in day 1 runoff decreased significantly $(p<0.0001)$ for the subsequent rainfall event $(D-8)$, and then increased again on day $35(p=0.0017)$.

The runoff mass loads in nanograms per minute of hormones and runoff rates for plots 1,2 , and 3 on day 1, 8, and 35 are shown in Figure 2. The concentration of each compound was multiplied by the runoff rate measured closest to each sampling time. The overall trend of mass load changes is consistent between different rainfall events, and the highest mass load of hormones correlated with the antecedent rainfall amount for $90 \%$ of the samples ( $p<0.05$; Table S8). Hormone loads were highest toward the end of each rainfall simulation. Because the simulated rainfall corresponded to an intense storm, it is likely that the early runoff concentrations are more indicative of what would be observed during a typical rainfall event. Significant correlations ( $R$ ranged from 0.67 to $0.98, p$ value $<0.05$; Table S8) were observed between antecedent rainfall amount and mass loads of androgens (i.e., androstenedione, cis-androsterone, dihydrotestosterone, and testosterone), estrogens (i.e., E1, $\alpha \mathrm{E} 2$, and $\beta \mathrm{E} 2$ ), and progesterone for the three experimental plots on days 1,8 , and 35 . This observation is in agreement with a recent study that also reported significant correlations between antecedent rainfall amounts and mass exports of estrogens from poultry litter amended soil and suggests that mass exports and concentrations of estrogens do not necessarily monotonically decrease with successive rainfall events. ${ }^{23}$ This observation is consistent with our findings with respect to E1, which actually increased in concentration on day 8 compared to day 1. Collectively, our results suggest that higher rainfall amount may promote runoff with higher hormone loads from both manure- and biosolids-amended soils.

Whereas both $\alpha \mathrm{E} 2$ and $\beta \mathrm{E} 2$ were observed at very low concentrations $\left(<\sim 2 \mathrm{ng} \mathrm{L}^{-1}\right)$ in runoff, on day $35 \mathrm{E} 1$ was present in runoff at much higher concentration $\left(>10 \mathrm{ng} \mathrm{L}^{-1}\right)$. The greater E1 concentrations on day 35 are most likely due to release from the biosolids and to a smaller extent biodegradation of $\beta \mathrm{E} 2$ to $\mathrm{E} 1$, suggested by the observation that the concentration profile of $\beta \mathrm{E} 2$ followed the profile of $\mathrm{E} 1$ (Figure 1). Interestingly, a recent study found that E1 had a higher soil sorption coefficient $\left(K_{\mathrm{d}}=33 \mathrm{~L} \mathrm{~kg}^{1-}\right.$ soil $)$ and a higher soil sorption coefficient per unit organic carbon $\left(K_{\mathrm{oc}}=\right.$ $\left.1557 \mathrm{~L} \mathrm{~kg}^{1-}\right)$ than $\beta \mathrm{E} 2\left(K_{\mathrm{d}}=23 \mathrm{~L} \mathrm{~kg}^{1-}\right.$ soil and $K_{\mathrm{oc}}=1082 \mathrm{~L}$ $\left.\mathrm{kg}^{1-}\right)$ based on investigations of 121 surface $(0-15 \mathrm{~cm})$ soils. ${ }^{36}$ Thus, stronger sorption of $\beta \mathrm{E} 2$ is not a likely explanation for this observation. However, it is likely that some $\alpha \mathrm{E} 2$ and $\beta \mathrm{E} 2$ were degraded to $\mathrm{E}^{23,37}$ in the biosolids-amended soil and may, in part, have contributed to the observed concentration of E1 on the day 8 and day 35 .

There was no natural precipitation between the day biosolids were applied to the field and one day after biosolids application. However, natural precipitation events did occur between days 1 and 8 after biosolids application $(25.4 \mathrm{~mm})$ and between day 8 and 35 after biosolids application $(10.4 \mathrm{~mm})$. The intermittent wetting and drying of the soil and applied biosolids throughout the entire study could influence the transport and biodegradation of hormones. In WWTPs, higher removal efficiencies have been found for androgens and progestogens (91-100\%) than for estrogens $(67-80 \%)$, with biodegradation being the major removal route. ${ }^{3}$ The absence of progesterone $(<8 \mathrm{ng}$
$\mathrm{L}^{-1}$ ) at day 8 and the reappearance at day 35 suggests either a slow desorption from the biosolids into the soil solution or microbial formation, perhaps from sterols. ${ }^{10}$ Further research is needed to determine if wetting the soil could induce rapid degradation of progesterone.

Kjær et al. ${ }^{22}$ assessed leaching of estrogens from manuretreated structured soils and found that leaching appears to be influenced by preferential transport, fast solute transport, and drainage water dynamics. Although our results demonstrate that hormones do run off from biosolids-amended soils, additional studies are needed to address the mechanisms of transport (e.g., leaching potential of hormones from biosolidsamended soils). The past history of conventional-tillage on the reduced-tillage plots could have resulted in the development of impeding layers, which could have reduced infiltration and enhanced runoff. ${ }^{38}$ Jenkins et al. ${ }^{12}$ observed higher exports of $\beta \mathrm{E} 2$ in runoff from conventional-tillage $\left(1300 \mu \mathrm{g} \mathrm{ha}^{-1}\right)$ versus no tillage $\left(600 \mu \mathrm{g} \mathrm{ha}^{-1}\right)$ with poultry litter plots. Further research is also required to evaluate the potential for hormone transport from biosolids-amended soils with different agricultural management practices.

Steroid Hormone Fractionation between Dissolved and Suspended-Particle Bound Phases. For this study, dissolved-phase hormones are operationally defined as the fraction of hormones in water that pass through a $0.7-\mu \mathrm{m}$ glassfiber filter. The runoff samples were filtered the day after collection and stored at $-60{ }^{\circ} \mathrm{C}$ until analysis. Likewise, particle-bound hormones are defined as the fraction of hormones that are retained on the same filter. The percentages of hormones bound to the suspended-particle phase and in the dissolved phase were compared (Figure 3 ) to determine the importance of each phase for hormone transport. These comparisons were made for compounds that were present in the day 1 and 8 samples from all 3 plots, and day 35 samples from plots 1 and 2 .

Coprostanol (>98\%) and cholesterol (>98\%) were present primarily in the suspended particles (i.e., particles $>0.7 \mu \mathrm{m}$ ), $\beta \mathrm{E} 2$ was present approximately $50 \%$ bound to suspended particles, while the rest of the hormones remained primarily in the dissolved phase. At 1 day after biosolids application, the percentage of particle-associated hormones varied from $<0.8$ to $16 \%$ for testosterone, 6 to $17 \%$ androstenedione, 6 to $16 \%$ for cis-androsterone, 22 to $45 \%$ for $\mathrm{E} 1$, and 46 to $63 \%$ for $\beta \mathrm{E} 2$ based on the results from three experimental plots. More than $95 \%$ of progesterone was observed in the dissolved phase. Similar trends were observed 8 days and 35 days after biosolids application (Figure 3), but with a higher frequency of nondetections.

Coprostanol and cholesterol were present on suspended particles to a greater extent than estrogens, androgens, and progesterone, likely due to their hydrophobic properties. In general, the mean percentage of particle-bound hormones observed in this study followed the order sterols $\gg$ estrogens $>$ androgens and progesterone. This pattern is in partial agreement with previous studies ${ }^{39,40}$ and may be due to the lower water solubility of estrogens $\left(S_{\mathrm{w}}=\sim 1\right.$ to $\left.4 \mathrm{mg} \mathrm{L}^{-1}\right)$ than androgens $\left(S_{\mathrm{w}}=\sim 20\right.$ to $\left.875 \mathrm{mg} \mathrm{L}^{-1}\right)$ and progesterone $\left(S_{\mathrm{w}}=\right.$ $8.81 \mathrm{mg} \mathrm{L}^{-1}$ ) (Table S1). The log $K_{\mathrm{ow}}$ for progesterone (3.67 to 3.87 ) is higher than the $\log K_{\mathrm{ow}}$ values (1.92 to 3.69) for the androgens but similar to or lower than the $\log K_{\mathrm{ow}}$ (3.13 to 4.01) of $\mathrm{E} 1$ and $\beta \mathrm{E} 2$ (Table $\mathrm{S} 1$ ).

Physicochemical properties could also influence distribution of hormones between particles and aqueous phases. Dipole 


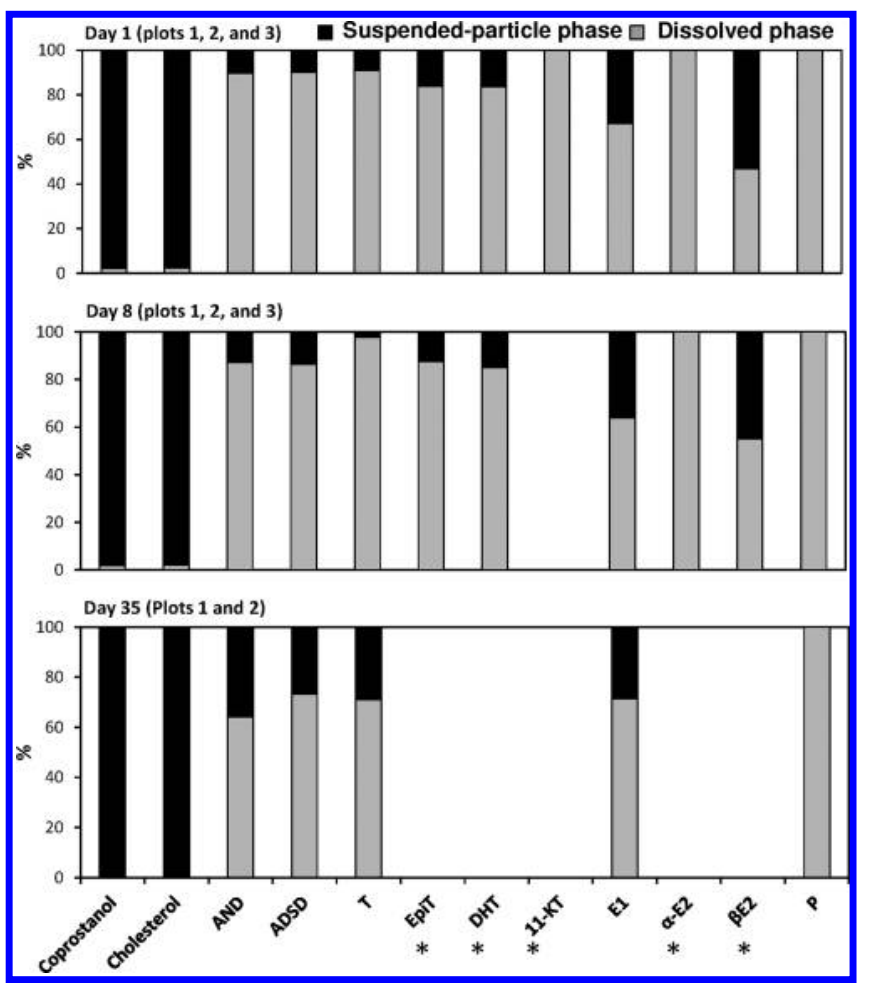

Figure 3. Mean (three sampling times) coprostanol, cholesterol, and hormone percentages in the dissolved (including $<0.7-\mu \mathrm{m}$ particles) and suspended-particle bound phases in runoff samples collected from plots 1-3 during the rainfall events 1,8 , and 35 days after biosolids application (AND: cis-androsterone; ADSD: androstenedione; $\mathrm{T}$ : testosterone; EpiT: epitestosterone; DHT: dihydrotestosterone; 11$\mathrm{KT}$ : 11 -ketotestosterone; E1: estrone; $\alpha \mathrm{E} 2$ : $17 \alpha$-estradiol; $\beta \mathrm{E} 2: 17 \beta$ estradiol; P: progesterone). No measurements were made for plot 3 on day 35 . * Compounds were observed at concentrations near their detection limit which may lead to larger errors.

effects, which could influence particle association by interaction with charged clay particles, would be stronger for estrogens than the other compounds due to the presence of a phenol substituent rather than a conjugated ketone in the A-ring of the steroid. ${ }^{39}$ The fraction of biosolids in the soil is relatively low so there could be some polar interactions occurring with clays. ${ }^{40}$ Indeed, Khan et al. ${ }^{41}$ and Mashtare et al. ${ }^{42}$ show differences in sorption to agricultural soils between stereoisomers of estradiol and trenbolone, a synthetic androgen, with stronger partitioning observed for the $17 \beta$ isomer relative to the $17 \alpha$ isomer. Because stereochemical configuration does not affect $K_{\text {ow }}$ values, they attributed the observed differences to polar interactions between the hormones and soil mineral phases. The present study results confirm that the $17 \beta$ stereoisomers of testosterone and estradiol are more strongly associated with particulate matter than the $17 \alpha$ stereoisomers (Figure 3 ).

Finally, three compounds were observed at concentrations near their detection limit in the dissolved phase and not detected in the suspended-particle phase. Therefore, for progesterone, $\alpha \mathrm{E} 2$, and 11-ketotestosterone the minimum fraction present in the dissolved phase is reported. However, the failure to detect progesterone, 11-ketotestosterone, and $\alpha \mathrm{E} 2$ in particulate samples, coupled with detection limits that approach their aqueous concentrations, precludes reliable determination of their partitioning behavior.

Esperanza et al. ${ }^{43}$ assessed the fate of sex hormones in two pilot-scale municipal WWTPs and found that testosterone, androstenedione, and progesterone tended to remain in the dissolved phase (filtrate; passing through $1-\mu \mathrm{m}$ filters) and did not partition significantly to the solids. It is noted that the dissolved and suspended-particle phases were separated by a standard $0.7-\mu \mathrm{m}$ glass-fiber filter in the present study. Interestingly, we did not detect progesterone in the particulate fraction (Figure 3). Thus, it is likely that the aqueous fraction contained small particles and/or colloids containing sorbed steroid hormones. Holbrook et al. ${ }^{44}$ observed that up to $60 \%$ of $\beta \mathrm{E} 2$ and EE2 in wastewater is associated with aqueous colloidal material, but the $\log K_{\mathrm{oc}}$ values and $\log K_{\mathrm{ow}}$ values were not well-correlated with estrogen sorption to colloids. Similar poor linear relationships between $\log K_{\mathrm{ow}}$ and partitioning to colloidal organic carbon for $\mathrm{E} 1, \beta \mathrm{E} 2$, and $\mathrm{EE} 2$ have been shown previously. ${ }^{45}$ This further suggest that hydrophobic partitioning does not completely explain sorption behavior of hormones and that aquatic colloids may play an important role in the environmental behavior of steroid hormones. Additional research is needed to evaluate the physicochemical properties of colloids that influence transport of hormones.

Environmental Implications. The present study assessed the runoff potential for estrogens, androgens, and progestogens from agricultural test plots receiving a first-time application of biosolids. Three factors need to be considered when evaluating this data set: (1) the data likely represent a worst-case scenario (100-year rainfall event or $65 \mathrm{~mm} \mathrm{~h}^{-1}$ ) for runoff conditions at our field site, (2) while hormones were present in runoff from biosolids-amended fields, farther transport to surface waters, wetlands, or elsewhere on the landscape, requires additional study, and (3) if hormones did reach receiving waters, concentrations likely would be diluted and impact on aquatic organisms would thus be mitigated. Nevertheless, our findings demonstrate that hormones can be present in runoff from biosolids-amended agricultural fields, and that relatively high concentrations of androgens and progesterone are likely to be found in the surface runoff even after multiple heavy rainfall events and over one month following the original application of biosolids. The hormone mass load correlated with antecedent rainfall amount, emphasizing that a heavy rainstorm event will promote a pulse of hormones in runoff. This suggests that biosolids could be an important source of hormones to surface waters. The concentrations of estrogens and androgens, in particular androstenedione, detected in this study are higher than concentrations that have been shown to alter biochemistry and behavior in susceptible fish. ${ }^{1,46-50}$ The lowest observed effect level (LOEL) affecting vitellogenin production in juvenile female rainbow trout was found to be as low as $3.3 \mathrm{ng} \mathrm{E1/L.}{ }^{51}$ Furthermore, the possible impact of hormone exposure on terrestrial organisms has not been documented. However, Kinney et al. ${ }^{52}$ demonstrated the uptake of wastewater-derived compounds by earthworms and this suggests the potential for bioaccumulation of these compounds in the food web. Additional research is required to evaluate the potential for hormone transport from biosolids-amended soils with different soil composition, means of biosolids application, and climate conditions (e.g., precipitation rate) and across longer distances.

\section{ASSOCIATED CONTENT}

\section{Supporting Information}

Material supporting detailed description of the analytical methods, tables and figures showing chemical structures and physicochemical properties of target compounds (Table S1), the physical and chemical properties of soils (Table S2), 
concentrations of target compounds in biosolids (Table S5) and runoff samples (Table S6 and S7), statistical analysis (Table S8), the experimental design (Figure S1), the antecedent soil moisture (Figure S2), and additional results of average concentration of hormones distinguishing the three different plots (Figure S3 to S5). This material is available free of charge via the Internet at http://pubs.acs.org.

\section{AUTHOR INFORMATION}

\section{Corresponding Author}

*Phone: +1-970-491-6235; fax: +1-970-491-0564; e-mail: thomas.borch@colostate.edu.

\section{Notes}

The authors declare no competing financial interest.

\section{ACKNOWLEDGMENTS}

This research was supported by the Colorado Water Institute (CWI) and, in part, by a National Science Foundation (NSF) CAREER Award (EAR 0847683) to T.B. Support also was provided by the USGS Toxic Substances Hydrology Program's Emerging Contaminant Project. We thank Dana Kolpin (USGS), Tracy Yager (USGS), William Foreman (USGS), Corey Stephens (USGS), Jeff Writer (USGS), Adriane Elliott (CSU), and Kathy Doesken (CSU) for their invaluable technical assistance. We also thank Mr. Doug Lingo for the access to his farm. Any use of trade, firm, or product names in the paper is for descriptive purposes only and does not imply endorsement by the U.S. Government.

\section{REFERENCES}

(1) Vajda, A. M.; Barber, L. B.; Gray, J. L.; Lopez, E. M.; Woodling, J. D.; Norris, D. O. Reproductive disruption in fish downstream from an estrogenic wastewater effluent. Environ. Sci. Technol. 2008, 42 (9), 3407-3414.

(2) Kolodziej, E. P.; Harter, T.; Sedlak, D. L. Dairy wastewater, aquaculture, and spawning fish as sources of steroid hormones in the aquatic environment. Environ. Sci. Technol. 2004, 38 (23), 6377-6384.

(3) Chang, H.; Wan, Y.; Wu, S.; Fan, Z.; Hu, J. Occurrence of androgens and progestogens in wastewater treatment plants and receiving river waters: Comparison to estrogens. Water Res. 2011, 45 (2), $732-740$.

(4) Ying, G. G.; Kookana, R. S.; Kumar, A.; Mortimer, M. Occurrence and implications of estrogens and xenoestrogens in sewage effluents and receiving waters from South East Queensland. Sci. Total Environ. 2009, 407 (18), 5147-5155.

(5) Pal, A.; Gin, K. Y. H.; Lin, A. Y. C.; Reinhard, M. Impacts of emerging organic contaminants on freshwater resources: Review of recent occurrences, sources, fate and effects. Sci. Total Environ. 2010, 408 (24), 6062-6069.

(6) Wang, Y. Q.; Hu, W.; Cao, Z. H.; Fu, X. Q.; Zhu, T. Occurrence of endocrine-disrupting compounds in reclaimed water from Tianjin, China. Anal. Bioanal. Chem. 2005, 383 (5), 857-863.

(7) Swartz, C. H.; Reddy, S.; Benotti, M. J.; Yin, H. F.; Barber, L. B.; Brownawell, B. J.; Rudel, R. A. Steroid estrogens, nonylphenol ethoxylate metabolites, and other wastewater contaminants in groundwater affected by a residential septic system on Cape Cod, MA. Environ. Sci. Technol. 2006, 40 (16), 4894-4902.

(8) Chen, T. S.; Chen, T. C.; Yeh, K. J. C.; Chao, H. R.; Liaw, E. T.; Hsieh, C. Y.; Chen, K. C.; Hsieh, L. T.; Yeh, Y. L. High estrogen concentrations in receiving river discharge from a concentrated livestock feedlot. Sci. Total Environ. 2010, 408 (16), 3223-3230.

(9) Gadd, J. B.; Tremblay, L. A.; Northcott, G. L. Steroid estrogens, conjugated estrogens and estrogenic activity in farm dairy shed effluents. Environ. Pollut. 2010, 158 (3), 730-736.
(10) Mansell, D. S.; Bryson, R. J.; Harter, T.; Webster, J. P.; Kolodziej, E. P.; Sedlak, D. L. Fate of endogenous steroid hormones in steer feedlots under simulated rainfall-induced runoff. Environ. Sci. Technol. 2011, 45 (20), 8811-8818.

(11) Jacobsen, A.-M.; Lorenzen, A.; Chapman, R.; Topp, E. Persistence of testosterone and 17 beta-estradiol in soils receiving swine manure or municipal biosolids. J. Environ. Qual. 2005, 34 (3), 861-871.

(12) Jenkins, M. B.; Endale, D. M.; Schomberg, H. H.; Hartel, P. G.; Cabrera, M. L. 17 beta-Estradiol and testosterone in drainage and runoff from poultry litter applications to tilled and no-till crop land under irrigation. J. Environ. Manage. 2009, 90 (8), 2659-2664.

(13) Gall, H. E.; Sassman, S. A.; Lee, L. S.; Jafvert, C. T. Hormone discharges from a midwest tile-drained agroecosystem receiving animal wastes. Environ. Sci. Technol. 2011, 45 (20), 8755-8764.

(14) Yang, Y.-Y.; Borch, T.; Young, R. B.; Goodridge, L. D.; Davis, J. G. Degradation kinetics of testosterone by manure-borne bacteria: Influence of temperature, $\mathrm{pH}$, glucose amendments, and dissolved oxygen. J. Environ. Qual. 2010, 39 (4), 1153-1160.

(15) Yang, Y.-Y.; Pereyra, L. P.; Young, R. B.; Reardon, K. F.; Borch, $\mathrm{T}$. Testosterone-mineralizing culture enriched from swine manure: Characterization of degradation pathways and microbial community composition. Environ. Sci. Technol. 2011, 45 (16), 6879-6886.

(16) Bradley, P. M.; Barber, L. B.; Chapelle, F. H.; Gray, J. L.; Kolpin, D. W.; McMahon, P. B. Biodegradation of 17 beta-estradiol, estrone and testosterone in stream sediments. Environ. Sci. Technol. 2009, 43 (6), 1902-1910.

(17) Barber, L. B.; Keefe, S. H.; LeBlanc, D. R.; Bradley, P. M.; Chapelle, F. H.; Meyer, M. T.; Loftin, K. A.; Kolpin, D. W.; Rubio, F. Fate of sulfamethoxazole, 4-nonylphenol, and 17 beta-estradiol in groundwater contaminated by wastewater treatment plant effluent. Environ. Sci. Technol. 2009, 43 (13), 4843.

(18) Layton, A. C.; Gregory, B. W.; Seward, J. R.; Schultz, T. W.; Sayler, G. S. Mineralization of steroidal hormones by biosolids in wastewater treatment systems in Tennessee U.S.A. Environ. Sci. Technol. 2000, 34 (18), 3925-3931.

(19) Citulski, J. A.; Farahbakhsh, K. Fate of endocrine-active compounds during municipal biosolids treatment: A review. Environ. Sci. Technol. 2010, 44 (22), 8367-8376.

(20) Stumpe, B.; Marschner, B. Long-term sewage sludge application and wastewater irrigation on the mineralization and sorption of 17 beta-estradiol and testosterone in soils. Sci. Total Environ. 2007, 374 (2-3), 282-291.

(21) Stumpe, B.; Marschner, B. Dissolved organic carbon from sewage sludge and manure can affect estrogen sorption and mineralization in soils. Environ. Pollut. 2010, 158 (1), 148-154.

(22) Kjaer, J.; Olsen, P.; Bach, K.; Barlebo, H. C.; Ingerslev, F.; Hansen, M.; Sorensen, B. H. Leaching of estrogenic hormones from manure-treated structured soils. Environ. Sci. Technol. 2007, 41 (11), 3911-3917.

(23) Dutta, S.; Inamdar, S.; Tso, J.; Aga, D. S.; Sims, J. T. Free and conjugated estrogen exports in surface-runoff from poultry litteramended soil. J. Environ. Qual. 2010, 39 (5), 1688-1698.

(24) Nichols, D. J.; Daniel, T. C.; Moore, P. A.; Edwards, D. R.; Pote, D. H. Runoff of estrogen hormone 17 beta-estradiol from poultry litter applied to pasture. J. Environ. Qual. 1997, 26 (4), 1002-1006.

(25) Finlay-Moore, O.; Hartel, P. G.; Cabrera, M. L. 17 beta-estradiol and testosterone in soil and runoff from grasslands amended with broiler litter. J. Environ. Qual. 2000, 29 (5), 1604-1611.

(26) Jenkins, R. L.; Wilson, E. M.; Angus, R. A.; Howell, W. M.; Kirk, $\mathrm{M}$. Androstenedione and progesterone in the sediment of a river receiving paper mill effluent. Toxicol. Sci. 2003, 73 (1), 53-59.

(27) Kinney, C. A.; Furlong, E. T.; Zaugg, S. D.; Burkhardt, M. R.; Werner, S. L.; Cahill, J. D.; Jorgensen, G. R. Survey of organic wastewater contaminants in biosolids destined for land application. Environ. Sci. Technol. 2006, 40 (23), 7207-7215.

(28) Bevacqua, C. E.; Rice, C. P.; Torrents, A.; Ramirez, M. Steroid hormones in biosolids and poultry litter: A comparison of potential environmental inputs. Sci. Total Environ. 2011, 409 (11), 2120-2126. 
(29) Miller, W. P. A solenoid-operated, variable intensity rainfall simulator. Soil Sci. Soc. Am. J. 1987, 51 (3), 832-834.

(30) Davis, J. G.; Truman, C. C.; Kim, S. C.; Ascough, J. C.; Carlson, K. Antibiotic transport via runoff and soil loss. J. Environ. Qual. 2006, 35 (6), 2250-2260.

(31) Furlong, E. T.; Gray, J. L.; Quanrud, D. M.; Teske, S. S.; Werner, S. L.; Esposito, K. E.; Marine, J.; Ela, W. P.; Zaugg, S. D.; Phillips, P. J.; Stinson, B. Pharmaceuticals, hormones, anthropogenic waste indicators, and total estrogenicity in liquid and solid samples from municipal sludge stabilization and dewatering. Open-File Rep.-U.S. Geol. Surv. 2011, 1132, 77.

(32) Foreman, W. T.; Gray, J. L.; ReVello, R. C.; Lindley, C. E.; Losche, S. A.; Barber, L. B. Determination of Steroid Hormones in Filtered and Unfiltered Water by Solid-Phase Extraction, Derivatization and Gas Chromatography with Tandem Mass Spectrometry; U.S. Geological Survey Techniques and Methods, 2011.

(33) Burkhardt, M. R; ReVello, R. C.; Smith, S. G.; Zaugg, S. D. Pressurized liquid extraction using water/isopropanol coupled with solid-phase extraction cleanup for industrial and anthropogenic wasteindicator compounds in sediment. Anal. Chim. Acta 2005, 534 (1), $89-100$.

(34) Zheng, W.; Yates, S. R.; Bradford, S. A. Analysis of steroid hormones in a typical airy waste disposal system. Environ. Sci. Technol. 2008, 42 (2), 530-535.

(35) Casey, F. X. M.; Hakk, H.; Simunek, J.; Larsen, G. L. Fate and transport of testosterone in agricultural soils. Environ. Sci. Technol. 2004, 38 (3), 790-798.

(36) Caron, E.; Farenhorst, A.; Zvomuya, F.; Gaultier, J.; Rank, N.; Goddard, T.; Sheedy, C. Sorption of four estrogens by surface soils from 41 cultivated fields in Alberta, Canada. Geoderma 2010, 155 (12), 19-30.

(37) Colucci, M. S.; Bork, H.; Topp, E. Persistence of estrogenic hormones in agricultural soils: I. 17 beta-estradiol and estrone. $J$. Environ. Qual. 2001, 30 (6), 2070-2076.

(38) Lal, R. No-tillage effects on soil properties under different crops in Western Nigeria. Soil Sci. Soc. Am. J. 1976, 40 (5), 762-768.

(39) Kubli-Garfias, C. Comparative study of the electronic structure of estradiol, epiestradiol and estrone by ab initio theory. Theochem.-J. Mol. Struct. 1998, 452, 175-183.

(40) Hofstetter, T. B.; Neumann, A.; Schwarzenbach, R. P. Reduction of nitroaromatic compounds by $\mathrm{Fe}$ (II) species associated with ironrich smectites. Environ. Sci. Technol. 2006, 40 (1), 235-242.

(41) Khan, B.; Qiao, X. L.; Lee, L. S. Stereoselective sorption by agricultural soils and liquid-liquid partitioning of trenbolone (17 alpha and 17 beta) and trendione. Environ. Sci. Technol. 2009, 43 (23), $8827-8833$.

(42) Mashtare, M. L.; Khan, B.; Lee, L. S. Evaluating stereoselective sorption by soils of 17 alpha-estradiol and 17 beta-estradiol. Chemosphere 2011, 82 (6), 847-852.

(43) Esperanza, M.; Suidan, M. T.; Marfil-Vega, R.; Gonzalez, C.; Sorial, G. A.; McCauley, P.; Brenner, R. Fate of sex hormones in two pilot-scale municipal wastewater treatment plants: Conventional treatment. Chemosphere 2007, 66 (8), 1535-1544.

(44) Holbrook, R. D.; Love, N. G.; Novak, J. T. Sorption of 17-betaestradiol and 17 alpha-ethinylestradiol by colloidal organic carbon derived from biological wastewater treatment systems. Environ. Sci. Technol. 2004, 38 (12), 3322-3329.

(45) Liu, R. X.; Wilding, A.; Hibberd, A.; Zhou, J. L. Partition of endocrine-disrupting chemicals between colloids and dissolved phase as determined by cross-flow ultrafiltration. Environ. Sci. Technol. 2005, 39 (8), 2753-2761.

(46) Baronti, C.; Curini, R.; D’Ascenzo, G.; Di Corcia, A.; Gentili, A.; Samperi, R. Monitoring natural and synthetic estrogens at activated sludge sewage treatment plants and in a receiving river water. Environ. Sci. Technol. 2000, 34 (24), 5059-5066.

(47) Brian, J. V.; Harris, C. A.; Scholze, M.; Kortenkamp, A.; Booy, P.; Lamoree, M.; Pojana, G.; Jonkers, N.; Marcomini, A.; Sumpter, J. P. Evidence of estrogenic mixture effects on the reproductive performance of fish. Environ. Sci. Technol. 2007, 41 (1), 337-344.
(48) Coe, T. S.; Hamilton, P. B.; Hodgson, D.; Paull, G. C.; Stevens, J. R.; Sumner, K.; Tyler, C. R. An environmental estrogen alters reproductive hierarchies, disrupting sexual selection in group-spawning fish. Environ. Sci. Technol. 2008, 42 (13), 5020-5025.

(49) Thorpe, K. L.; Maack, G.; Benstead, R.; Tyler, C. R. Estrogenic wastewater treatment works effluents reduce egg production in fish. Environ. Sci. Technol. 2009, 43 (8), 2976-2982.

(50) Sorensen, P. W.; Pinillos, M.; Scott, A. P. Sexually mature male goldfish release large quantities of androstenedione into the water where it functions as a pheromone. Gen. Comp. Endrocrinol. 2005, 140 (3), 164-175.

(51) Thorpe, K. L.; Cummings, R. I.; Hutchinson, T. H.; Scholze, M.; Brighty, G.; Sumpter, J. P.; Tyler, C. R. Relative potencies and combination effects of steroidal estrogens in fish. Environ. Sci. Technol. 2003, 37 (6), 1142-1149.

(52) Kinney, C. A.; Furlong, E. T.; Kolpin, D. W.; Burkhardt, M. R.; Zaugg, S. D.; Werner, S. L.; Bossio, J. P.; Benotti, M. J. Bioaccumulation of pharmaceuticals and other anthropogenic waste indicators in earthworms from agricultural soil amended with biosolid or swine manure. Environ. Sci. Technol. 2008, 42 (6), 1863-1870. 